\title{
Harmonizing WHO's International Classification of Diseases (ICD) and International Classification of Functioning, Disability and Health (ICF): importance and methods to link disease and functioning
}

Reuben Escorpizo 1,2,3* Nenad Kostanjsek ${ }^{4}$, Cille Kennedy ${ }^{5}$, Molly Meri Robinson Nicol ${ }^{4}$, Gerold Stucki ${ }^{2,3,6}$,

Tevfik Bedirhan Üstün ${ }^{4}$ and on behalf of the Functioning Topic Advisory Group (fTAG) of the ICD-11 Revision

\begin{abstract}
Background: To understand the full burden of a health condition, we need the information on the disease and the information on how that disease impacts the functioning of an individual. The ongoing revision of the International Classification of Diseases (ICD) provides an opportunity to integrate functioning information through the International Classification of Functioning, Disability and Health (ICF).

Discussion: Part of the ICD revision process includes adding information from the ICF by way of "functioning properties" to capture the impact of the disease on functioning. The ICD content model was developed to provide the structure of information required for each ICD-11 disease entity and one component of this content model is functioning properties. The activities and participation domains from ICF are to be included as the value set for functioning properties in the ICD revision process.

Summary: The joint use of ICD and ICF could create an integrated health information system that would benefit the implementation of a standard language-based electronic health record to better capture and understand disease and functioning in healthcare.
\end{abstract}

Keywords: International classification of diseases, ICF, Classification, Functioning, ICD revision, Disability

\section{Background}

Describing and understanding the relationship between disease and functioning requires the use of two of the World Health Organization's classifications systems: the International Classification of Diseases (ICD) [1] and the International Classification of Functioning, Disability and Health (ICF) [2]. The ICD classifies disease entities and other health conditions to gather diagnostic information, while the ICF classifies domains of functioning

\footnotetext{
* Correspondence: rescor@lsuhsc.edu

'Department of Physical Therapy, Louisiana State University Health Sciences Center, New Orleans, LA, USA

${ }^{2}$ ICF Research Branch in cooperation with the WHO Collaborating Centre for the Family of International Classifications in Germany (DIMDI), Nottwil,

Switzerland

Full list of author information is available at the end of the article
}

and disability in terms of body functions and structures or activities and participation at the body, person and societal levels. The ICD and the ICF classification systems are intended by WHO to complement each other so as to capture and provide the full picture of health or health-related state of an individual. Currently, however, there is no standard platform in which the disease and its impact on functioning are concurrently used within an integrated health information system. Efforts to capture the impact of a disease in a structured and systematic way have so far been hampered by the failure to link the ICD and the ICF at a conceptual and operational level. 


\section{ICD revision}

The ICD is undergoing its $11^{\text {th }}$ revision (ICD-11) [3] wherein part of the process is to add information from the ICF to the classification of diseases by adding "functioning properties" (i.e. ICF domains or codes) to capture the impact of the disease on functioning. In this integrated system, we want to be able to use universal domains (functioning properties) that depict the functioning of an individual by way of the ICF and also use information related to disease entities (ICD codes).

The process of revising the ICD is coordinated through Topic Advisory Groups (TAGs), each of which is responsible for different content areas. Responsible for the appropriate integration of the functioning properties is the Functioning Topic Advisory Group (fTAG), which consults with each of the TAGs regarding how to deal with functioning properties for their assigned ICD entities.

\section{Functioning properties of the ICD-11 content model}

The ICD-11 Content Model (Table 1) provides the structure of information detail required for each ICD-11 code included through the revision process $[3,4]$. In the ICF, "functioning" is an encompassing term for body functions, body structures, and activities and participation. In the ICD Content Model at this time, functioning properties only include the activities and participation component of the ICF. Activity is defined in the ICF as the "execution of a task or action by an individual", while participation is defined as "involvement in a life situation" [2]. Activities and participation are important in describing the impact of a disease because they capture the broad and relevant aspects of activity and involvement with society and life in general. Table 2 lists the ICF categories that are included in the value set for functioning properties. Hence, an ICD code would have a corresponding value set of functioning properties.

The task of populating the functioning properties in iCAT Before ICD-11 is completed, functioning properties will need to be populated for each ICD code. This task of population is being done and coordinated using the web-based International Collaborative Authoring Tool (iCAT) by content experts worldwide in three steps: [1] selection of functioning properties provided in iCAT (Table 2), [2] if an additional ICF domain or category needs to be added based on a published disease-specific ICF Core Set, then it is entered manually into the iCAT, and [3] use evidence from the literature (i.e. mini-review) by identifying the commonly used measures relevant to the disease of interest, and in those measures identify meaningful concepts of functioning with a focus on activities and participation in life situations, and then

Table 1 The Content Model of the ICD 11 [4]

Any category in ICD is represented by: TITLE of ENTITY: Name of disease, disorder, or syndrome

1. ICD Concept Title
1.1 Fully Specified Name
2. Classification Properties
2.1 Parents
2.2 Type
2.3 Use and Linearization(s)

3. Textual Definition(s)

4. Terms

$$
\begin{aligned}
& 4.1 \text { Base Index Terms } \\
& 4.2 \text { Inclusion Terms } \\
& 4.3 \text { Exclusions }
\end{aligned}
$$

5. Body Structure Description

5.1 Body System(s)

5.2 Body Part(s) [Anatomical Site(s)]

5.3 Histopathology

\section{Manifestation Properties}

6.1 Signs and Symptoms

6.2 Investigation Findings

\section{Causal Properties}

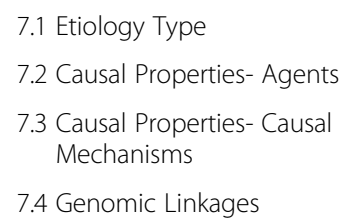

subsequently link the identified concepts to a specific domain in the ICF [5].

\section{Discussion}

Obtaining information about disease entities and their impact on functioning is not entirely new in the field of medicine and health. While the consideration of the disease and its impact on functioning has been in place, or at least acknowledged, for a long time, [6] there remain prevailing issues, such as the lack of wide dissemination and implementation extending beyond simple awareness $[7,8]$. The operationalization of integrated disease-and-functioning models currently varies, is fragmented across healthcare settings, and is perhaps
8. Temporal Properties

10. Functioning Properties

10.1 Impact on Activities and

10.2 Contextual Factors

1. Specific Condition Properties

11.1 Biological Sex

11.2 Life-Cycle Properties

12. Treatment Properties

13. Diagnostic Criteria

14. External Causes

1 Age of Occurrence \&
Occurrence Frequency
8.2 Development Course / Stage

9. Severity of Subtypes Properties 
Table 2 List of ICF-based functioning properties value set for an ICD code

\begin{tabular}{lll}
\hline Domains & ICF codes \\
\hline Understanding & Watching & $\mathrm{d} 110$ \\
& Listening & $\mathrm{d} 115$ \\
& Learning & $\mathrm{d} 130-\mathrm{d} 155$ \\
& Focusing attention & $\mathrm{d} 160$ \\
& Reading & $\mathrm{d} 166$ \\
& Writing & $\mathrm{d} 170$ \\
& Calculating & $\mathrm{d} 172$ \\
& Solving problems & $\mathrm{d} 175$ \\
& Other specified &
\end{tabular}

Communication Communicating with others d310

\begin{tabular}{|c|c|c|}
\hline & & d315 \\
\hline & & d320 \\
\hline & & d325 \\
\hline & Speaking & d330 \\
\hline & Starting a conversation & d3500 \\
\hline & Sustaining a conversation & d3501 \\
\hline & Other ... & \\
\hline Mobility & Standing & d4104 \\
\hline & Bending & d4105 \\
\hline & Maintaining a body position & $d 415$ \\
\hline & Transferring oneself & $d 420$ \\
\hline & Lifting and carrying objects & $\mathrm{d} 430$ \\
\hline & Fine hand use & $d 440$ \\
\hline & Hand and arm use & $d 445$ \\
\hline & Walking short distances & $d 4500$ \\
\hline & Walking long distances & $d 4501$ \\
\hline & Vigorous activities & $d 455$ \\
\hline & & d4303 \\
\hline & Moving around within home & d4600 \\
\hline & $\begin{array}{l}\text { Moving around outside the home } \\
\text { and other buildings }\end{array}$ & d4602 \\
\hline & Using transportation & $d 470$ \\
\hline & Driving & $\mathrm{d} 475$ \\
\hline & Other ... & \\
\hline Self-Care & Washing oneself & d510 \\
\hline & Caring for body parts & d520 \\
\hline & Urination & d5300 \\
\hline & Defecation & d5301 \\
\hline & Dressing & d540 \\
\hline & Eating & d550 \\
\hline & Drinking & d560 \\
\hline & $\begin{array}{l}\text { Managing one's health } \\
\text { (needs, assistance or oversight) }\end{array}$ & d570 \\
\hline & Other ... & \\
\hline
\end{tabular}

Table 2 List of ICF-based functioning properties value set for an ICD code (Continued)

\begin{tabular}{lll}
\hline $\begin{array}{ll}\text { Interpersonal } \\
\text { Relations }\end{array}$ & Making friends & $d 7200$ \\
& & $d 7500$ \\
& Engaging with other people & $d 740$ \\
& Maintaining family relationships & $d 750$ \\
& Dealing with strangers & $d 730$ \\
& Engaging in sexual relationships & $d 7702$
\end{tabular}

Other ...

Life Activities

Household

Shopping

d620

Cooking/preparing meals

d630

Doing housework

d640

Looking after/helping others

d660

Other ...

School

Attending school

d820

Learning a job (vocational training, d825 apprenticeship)

Going to university

d830

Other ...

Work and economic Engaging in paid work d850

life

Seeking employment d8450

Performing job related tasks d8451

Handling money d860

Other ...

Life management Undertaking a single task $\quad$ d210

Undertaking multiple tasks $\quad$ d220

Carrying out daily routine d230

Handling stress and psychological d240

demands

Other ...

Social Participation Taking part in social life $\quad$ d910

Sports d920

Travel d920

Visiting friends d9205

Human rights (e.g. self-determination, d940 equal opportunities)

Political life and citizenship (e.g. voting) d950

Other ...

Children and Youth

d140

Learning to write d145

Learning to calculate d150

Communicating with others $\quad$ d310

d315

d320 
Table 2 List of ICF-based functioning properties value set for an ICD code (Continued)

$\begin{array}{ll}\text { Speaking } & \mathrm{d} 330 \\ \text { Attending school } & \mathrm{d} 8201 \\ \text { Taking exams } & \mathrm{d} 8202 \\ \text { Playing with others } & \mathrm{d} 880 \\ & \mathrm{~d} 9200\end{array}$

more commonly observed in healthcare systems with medium to advanced infrastructures and access to resources. We can do a better job at facilitating an integrated disease-and-functioning model across systems from low to high resource countries. Moreover, the ongoing ICD revision would make the assessment and documentation of a comprehensive set of information about a disease entity as broad and as inclusive as possible; at the same time utilizing the standard and common language of the ICF on functioning. This information will consist of biomedical and biopsychosocial aspects of the disease that will provide clinicians and users alike an integrated and unified ICD-ICF platform and which will be helpful in interdisciplinary communication towards a concerted planning of care ultimately benefiting the patients.

The ICD-11 is due to be launched in 2015, and steps toward that goal are being pursued. Certainly there are challenges on our way, but there are also opportunities that are presented for users in the clinical and research communities to actively contribute in this huge endeavor by WHO and its collaborators worldwide. The unified ICD-ICF in the ICD-11 will allow for consistent terminologies to be used and to be harmonized across ICD and ICF and will provide holistic information about a disease entity and its impact on the functioning of an individual. Efforts are also currently being taken to facilitate the identification of the overlaps for ICD-11 disease entities and their titles with their conceptual equivalent in the ICF towards harmonization of ICD and ICF.

\section{Conclusion}

The joint use of the ICD and ICF towards an integrated health information model would, in our opinion, benefit medicine and health systems and would support the push for the implementation of a standard languagebased electronic health record system towards better health services planning and reimbursement.

\footnotetext{
Abbreviations

fTAG: Functioning Topic Advisory Group; iCAT: International Collaborative Authoring Tool; ICD: International Classification of Diseases; ICF: International Classification of Functioning, Disability and Health; TAG: Topic Advisory Group; WHO: World Health Organization.
}

\section{Competing interests}

The authors declare that they have no competing interests.

\section{Authors' contributions}

All authors provided concept/idea, consultation, and writing, and reviewed the manuscript before submission. All authors read and approved the final manuscript.

\section{Authors' information}

RE is Assistant Professor, Department of Physical Therapy, School of Allied Health Professions Louisiana State University Health Sciences Center, New Orleans LA USA; adjunct research scientist at the ICF Research Branch in cooperation with the WHO Collaborating Centre for the Family of International Classifications in Germany (DIMDI), Nottwil, (Switzerland); and the Swiss Paraplegic Research (SPF), Nottwil, Switzerland.

NK is technical officer at World Health Organization, Classifications, Terminologies and Standards (CTS), Department of Health Statistics and Informatics (HSI), Geneva, Switzerland.

CK is with the US Department of Health and Human Services, Office of Health Policy Washington D.C., USA.

MMRN is technical officer at World Health Organization, Classifications, Terminologies and Standards (CTS), Department of Health Statistics and Informatics (HSI), Geneva, Switzerland.

GS is director of the ICF Research Branch in cooperation with the WHO Collaborating Centre for the Family of International Classifications in Germany (DIMDI), Nottwil, (Switzerland) and the Swiss Paraplegic Research (SPF), Nottwil, Switzerland; is Professor and Chair at the Department of Health Sciences and Health Policy, University of Lucerne, Lucerne, Switzerland

TBU is head of WHO's Family of International Classifications, Geneva, Switzerland

R Escorpizo is an employee of the Louisiana State University Health Sciences Center (LSUHSC). This article was developed in his professional capacity and does not necessarily represent the views of LSUHSC.

C Kennedy is an employee of the Office of the Assistant Secretary for Planning and Evaluation (ASPE), Department of Health and Human Services (HHS). This article was developed in her professional capacity and does not necessarily represent the views of ASPE or HHS

\section{Acknowledgements}

Special thanks to Melissa Selb, ICF Research Branch coordinator in Nottwil, Switzerland and members of the functioning Topic Advisory Group.

\section{Author details}

${ }^{1}$ Department of Physical Therapy, Louisiana State University Health Sciences Center, New Orleans, LA, USA. ${ }^{2}$ ICF Research Branch in cooperation with the WHO Collaborating Centre for the Family of International Classifications in Germany (DIMDI), Nottwil, Switzerland. ${ }^{3}$ Swiss Paraplegic Research (SPF), Nottwil, Switzerland. ${ }^{4}$ World Health Organization, Classifications, Terminologies and Standards, Geneva, Switzerland. ${ }^{5}$ US Department of Health and Human Services, Office of Health Policy, Washington, DC, USA. ${ }^{6}$ Department of Health Sciences and Health Policy, University of Lucerne, Lucerne, Switzerland

Received: 11 March 2013 Accepted: 5 August 2013 Published: 12 August 2013

\section{References}

1. World Health Organization: International Classification of Diseases (ICD-10). Available from: http://www.who.int/classifications/icd/en/.

2. World Health Organization: International Classification of Functioning, Disability and Health. Geneva, Switzerland: World Health Organization; 2001.

3. World Health Organization: The International Classification of Diseases 11th Revision. 2012. Available from: http://www.who.int/classifications/icd/ revision/en/index.html.

4. Tu S, Bodenreider O, Celik C, Chute C, Heard S, Jakob R, et al: A content model for the ICD-11 revision: a technical report. Stanford, CA: Stanford Center for Biomedical Informatics Research; 2011. http://bmir.stanford.edu/ file_asset/index.php/1752/BMIR-2010-1405.pdf.

5. Cieza A, Geyh S, Chatterji S, Kostanjsek N, Ustun B, Stucki G: ICF linking rules: an update based on lessons learned. J Rehabil Med 2005, 37(4):212-218.

6. Engel GL: The need for a new medical model: a challenge for biomedicine. Science 1977, 196(4286):129-136. 
7. Alvarez AS, Pagani M, Meucci P: The clinical application of the biopsychosocial model in mental health: a research critique. Am J Phys Med Rehabil 2012, 91 (13 Suppl 1):S173-S180.

8. Alvarez AS: The application of the International Classification of Functioning, Disability, and Health in psychiatry: possible reasons for the lack of implementation. Am J Phys Med Rehabil 2012, 91 (13 Suppl 1):S69-S73.

doi:10.1186/1471-2458-13-742

Cite this article as: Escorpizo et al:: Harmonizing WHO's International Classification of Diseases (ICD) and International Classification of Functioning, Disability and Health (ICF): importance and methods to link disease and functioning. BMC Public Health 2013 13:742.

\section{Submit your next manuscript to BioMed Central and take full advantage of:}

- Convenient online submission

- Thorough peer review

- No space constraints or color figure charges

- Immediate publication on acceptance

- Inclusion in PubMed, CAS, Scopus and Google Scholar

- Research which is freely available for redistribution 